tudinal subdivision into three lobes, and several genera have been established of these aricient crustaceous inhabitants of our seas, which so much resemble chitons.

Numerous interesting forms of crustaceous animals present themselves in the London clay, and in most marine and even fresh-water formations, but generally much broken and compressed. Arachnida, myriapoda, and insects without number, occur in bituminised vegetallle resins or ambers of all geological epochs, in the more recent tertiary calcareous slates, and in gypsum and other deposits. Insects are found in the brown coal, and in the bituminous marl slate, and also entangled in the hard stalactites of chalcedony. The deciphering of these extinct forms of articulated animals, and the identifying of their species, are often important in geological inquiries, and require an acquaintance with the existing forms, and with the general plans of formation, which characterise the various groups. The accordance of these extinet forms of all epochs with the existing articulata, and the narrow limits of their variations, show not only that there is a remarkable unity of plan in this immense division of the animal kingdom, but that the same plan has been preserved from the beginning - that there is as much system and regularity and harmony in the laws which regulate the formation of these beings, and of the whole organic world, as are manifested in the rest of nature.

To-morrow I shall proceed to the skeleton of the molluscous classes.

CONTRIBUTIONS TO PATHOLOGY.

\section{No. III.*}

By John AleXa nder, M.D., one of the Medical Officers to the General Dispensary for Children, Munchester.

\section{VERMINATION.}

IN the autumn of $1830 \mathrm{my}$ attention was first particularly drawn to the subject of this paper from the following circumstance. I had been attending, for some days, a child, five years of age, labouring under convulsions of a very severe character, which had not appeared to give way in the least to the use of leeches, resicatories, cold applications, aperients, and subsequently, antispasmodics and the warm-bath; when, one evening after a lengthened attack, threatening dissolution, a worm, of the lumbricus teres species, was expelled, the exhausted child sank into

* Nos. I. and II. appeared in Nos. $45 \%$ and 495 of 'THE LaNCE'. a prolonged slumber, and had afterwards no return of the convulsions. The case attracted my especial notice on two accounts. The child was a firm-fleshed little fellow, with a countenance anything but verminative, and the most careful examination of the subsequent evacuations did not lead to the detection of any more worms, although appropriate medicines were persevered in for some time.

Vermination appears to have formed a favourite subject of speculation with the profession at all periods, for not merely have we on record, respecting it, the re. searches of Baglivi, Linnæus, Redi, Heister, Rudolphi, Butter, Lister, Black, Home, Simmons, Bremser, Schmucker, Hooper, Rush, Rhind, and a host of modern authors, but also the earlier views of Galen, Celsus, Avicenna, Pliny, and Hippocrates. In the succeeding cursory remarks, I purpose, chiefly, considering the disease as it is observed in early life.

Young children are subject to three kinds of worms, the ascarides or small seat. worm, the cucurbitina or flat short worm, and the lumbricus teres or round worm. The fourth variety of human worm, the tænia or tape-worm, I have in my own experience never known to be expelled by a young child, which, considering how much infested young persons are with worms, is somewhat singular ; and not the less so, as I have been told by practitioners of undoubted credibility that they have had scveral such cases. However, the records of medicine and personal observation dispose me to think the presence of tænia in the bowels of the young a rare disease, and I feel streng thened in this opinion by a late declaration of Dr. Elliotson (made at St. Thomas's Hospital), that he does not recollect ever having witnessed a single instance of it. In Germany and Switzerland I am aware this form of the disease does frequently affect the young.

The cause of vermination remains in utter obscurity. At one time it was said to be a weakened condition of the alimentary canal, overlooking the fact, that this local debility is sometimes more an effect than a cause of the presence of these parasitic animals. It was supposed by some writers that worms are engendered by their ova being swallowed amongst our food; but to this specious explanation it was objected, that the alimentary canal of animals is the only place in which certain worms are ever found, which, of course, would not be if the ova were imported from without. Again, other pathologists (Dr. Darwin amongst the number) have advocated the doctrine of worms being caused by a general inactivity of the ab. 
sorbent system ; but in what manner they have, unfortunately for us, not proceeded to demonstrate. Lastly, these worms have been supposed to originate in peculiar intestinal secretions, and the great moisture of the young child's bowels has been adduced to support the hypothesis. But a very brief review of the theories to be found in medical writings respecting vermination will, I think, justify the assertion that nothing definite or satisfactory is known upon the subject, and lead us to agree with Dr. Baillie, "that there is nothing in the economy of animals more obscure than the origin of intestinal worms."

The most common variety of vermination is that form induced by the ascarides. These ascarides or seat-worms, as they are sometimes called, are of a yellowish colour, vary as to length, being from a quarter to three-quarters of an inch long, and have for their habitat the lower part of the colon, and the whole rectum more particularly. Another form of ascarides is also frequently observed, wherein the worm is extremely small, and hence called the thread-worm. This latter species, viewed through the microscope, is chan racterised by a sharp head, and when exposed to the air immediately dies. The child infested with either variety is observed to have a pruritus equally of the anus and the nostrils, and to part with motions of a slimy character, small in quantity but frequently repeated. If the number of worms be considerable, some headach, restlessness, and symptoms of dyspepsia, supervene, but not of ten to any great extent. In these cases tolerably large enemata, consisting of bittci alces, susperded in any hland liquor, as gruel, linseed-tea, or olive oil give immediate, and, if repeated, complete relief. It is advisable, at the same time to administer small doses of scanmony and rhubarb to change the status or condition favourable to their regeneration. Enemata of Harrowgate water, the introduction of bougies sineared with mercurial ointment, and the smoke of tobacco and iced water, have severally had their advocates, but are now seldom used, less objectionable means answering every purpose.

Dr. Butter entertained the singular notion, that the presence of these worms was " Nature's remedy for destroying the superabounding morbid humours, and for stimulating the first passages by their crawling motions, and thereby assisting the peristaltic motion of the guts to carry off what remains of the offending load." Few persons at the present day will, I apprehend, be found to advocate Dr. Butter's ingenious view, or to think with Dr.
Parr, that " worms seem to form a part of a healthy constitution, and are scarcely injurious but from accidental circumstances." Finally, with regard to the ascarides, the curious, in such matters, on referring to the first volume of Medical Transactions, will there find a case related by Dr. Heberden, of ascarides infesting the bowels of an adult, and resisting every mode of treatment which that talented physician and other practitioners could think of. And in a late work published by Dr. Ryan, mention is made of these worms having been found in the bladder. Such cases, however, are not met with every day!

The symptoms attendant upon the presence of the cucurbitina, or flat short worm, are much more numerous, and of a more general character. The nasal and anal pruritus are less perceived, but present; the temper is iritable, and the child subject to grinding of the teeth, starting and low moaning during its slumber. The countenance is of a pasty look; the skin yellowish; the eye dull and frequently surrounded with a darkish areola ; the lips and nostrils are thick, swollen, and apparently odematous. The breath, in a morning, is fetid; the abdomen tumid, more or less hard, and frequently painful in the umbilical region. A sudder and severe pain at the stomach is a common symptom of vermination, as also are griping pains, suddenly arising and as suddenly subsiding. The child's urine is either very plentiful and pale, or, what is much more usual, scanty, thick, and of a white milky appearance. The fecal dejections are extremely irregular, at one time constipated, at another frequent, but always accompanied with more or less slimy and offensive mucus. This form of disorder is so common in the nursery, that $X$ need not dwell upon its description, but may now proceed to the treatment I have generally employed for its removal.

First, then, as to diet. Fresh vegetables, pastry, sweets, and salted food, should be interdicted. Stale wheaten bread, with milk, should form the evening and morning meal, and the meridian repast should consist of fresh animal food, such as mutton-chop, boiled fowl, or bcefsteak, in small quantity, with the bread before mentioned. To this may be added the various animal broths, and a littlc of the best rice in the form of pudding. It may be, and frequently is, objected, that the hitherto-indulged child will not take to this diet. My answer is, let the child fast until it will, and the period of abstinence is seldom a very protracted one. In dispensary practice, the cure of verminative disorders is constantly delayed by 
the parent being unable to afford the ap- mucus, which is said to form tho chopropriate food for the child; and owing to sen nidus of these worms, but as correctthis common occurrence we are rendered ing acidity, and thus acting medicinally painfully sensibie of the great importance, and chemically at the same time. of attachable to a rogulated diet in these cases.

Next as to medicine. It has been my custom to administer scammony, jalap, and calomel, in small closes, suited to the age, every alternate night at bed-time, succeded the monings following by a mi small dose of castor oil. There are two reasons upon which I think the preference th for small doses of apcrients might be justified. The first is, they have a better opportmity of cxerting their alterative eifect by being leisurely passed throurh the intestines; and the sccond is, that in the great majority of verminative cascs which I have witnesscd, the little sufferer is wore or less troubled with partial prolapsus of the lower gut, and it is scarcely uecessary to add, that powerful purgatives render this local debility a great source of distress; at the same time I fully concur with my esteencd friend and colleargue Mr. Stott, in thinking that the first purget. tive should be ju full dose, as a free criacuation of the large intestines gives marked relief to the accumnlative distention and anal bearing down accompanying these cases. Gamboge, from being tasteless, would be a purgatice peculiarly adapted, for children, list it is a drug which sometimes not merely produces great nausea, but fails altogether in acting as a purgative; hence I cannot recommend its general adoption. After the first passages have been reliered for a week, the spirit of empeutine mixed with castor oil inay next be given with the most salutary and marked effect, frequently removing humbeds of these ene. mies of chillhood at every dejection. The dose $I$ have generally adninistered to a child of fire years of age, has heen two drams, of each taken combined, on an empty stoniach; and as a little tomina sometimes accompanies this remedy (hirst recommended by Dr. Fenwick), the nother or nurse is directed to give oceasionaliy a little warm oatmeal gruel well nutmegred; and if the medicine indree temporary intoxication (not an unusual eflect), to lay the child on its bed till it pass over. Another node of exhibiting turpentine is, in milk swectened; and this form will sometimes agree with the child's stomach better than the one just mentioner.

Lime-water has been greatly lauded as a beverage in these cases, and I apprehend with some justice, as its certainly beneficial effect may be accounterl for, not merely on its aiding the removal of the folds. course the necessity for repeating or condetermined by the circunstances of individual cases; but even before they are discontinned (and as a general rule I have persercred in their exhibition for a fortnight), there is no objection to the use of some strengthening remedies with which the curc may he completed. For this latter purpose, the infusions of camomile, gentian, or calumba, with the powders of iron, bark, or rhubarb, will, any of them, answer very well.

ihe 1:se of cowhage (or the dolichos pruricns of Limmus) has been strongly urged on the profession by soreral practitioners, more particularly by Drs. Chamberlin, Macbrite, and Thomas, the latter of whom affirms, " that in several hum. dred cases in which he exhibited it in the West Indies, along with the submuriate of mereury and jalap, he never knew it once to fail." IIad the latter-mentioned remedies not the more important agency in the cure? The cowhage I have used, but not extensively enougl to authorise my venturing a decided opinion respecting it; and perhaps it is but.justice to Drs. Chamberlin, Macbride, and 'Thomas, to add, that in "the natural history of Guiana," an essay replete with inforination, Dr. Bancroft has recorded sentiments equally fa. vourable to this now-little-used medicine.

Of fern root (the basis of Madame Nouffler's celcbratel renedy), of valerian, asafoctida, in powder-iron filings, ground glass, \&c., I know little further than that they have been extensively used as vermifurys. The latter mentioned (if administcred) must be giren in very large doses, as their operation is purely me. chanical.

$\Lambda$ regulated diet, and daily exercise in the open air, are assuredly the best means of preventing a recurrence of the complaint under consideration. And one dictetic article I may here with propriety allude to, and that is common salt, although 1 cainot agree with Dr. Rush, in thinking it raluable as a means of reyow. ing worms, I ccrtainly do esteem it highly as a constituent in a child's food, well calculated to prevent their reyeneration in the intestines. The disease called the rot in shcep is accompanica, or caused, by great numbers of the fluke-worm being imbedded in, and destroying the liver, and every practical farmer well knows that sult given frecly, is almost invariahly a sure prevention of this plague of sheep- 
The destruction of the third variety of worm, to which children are liable-viz. the lumbricus teres, must he conducted on principles similar to those 1 have just described. Suffice it therefore to remark, that the ileum is the favourite habitat of the worm, that perseverance is indispensable for its removal, and that, although the least common, it is the most dangerous variety of vermination to which children are exposed, as it oftener leads to convulsions and death than any other. And here I may lay down a practical fact of great importance, that the non-detection in a child's motions of any worm, is not, by any means, conclusive evidence of the child being free from them. Therefore, if a young person labour under verminative symptoms, we should continue to exhibit appropriate medicines for some time, although apparently without effect, as it has been well observed by Dr. Armstrong, that worms may be so changed previous to expulsion, as not to be recornisable.

Vermination gives rise to many sympathetic affections in the brain, in the heart, in the lungs, in the stomach, and in the bladder. An instance of the first of these, viz. a sympathetic afiection of the brain, commences this paper, and since the time of its occurrence, I hare reveatedly met with similar ones, thotigh nove perhaps better marked. It becomes then a matter of practical import, to ascertain the features by which the young practitioner may he led to suspect at least the existence of vermination, when operating, as a cause of disorder, and wich that end in view, the following observations, brief thongh they be, may not altogether prove uselcss.

If a child, who has exhibited a fretful temper, has been irregular in its bowels, has a tumid abdomen, and has been subject to slimy evacuations, should be attacked with cerebral symptoms, they should first be met, almost exclusively, by active purgatives, for, with the removal of the cause, will the apparently cerebral disorder subside. Again, should a child so circumstanced exhibit still stronger symptoms of affection of the brain, as dilated pupil and epileptic paroxysms, without a corresponding affection of the pulse and stin, vermination is probably the source of disturbance.

Should a young person be troubled with pain, sometimes referred to the side, sometimes to the epigastrium, and more firequently to the umbilical region, and be seeking relief for a tickling cough, unat. tended with expectoration though considerable emaciation, anthelmintics will frequently prove the best remedies that can be exhibited, as this is often but another form of the disorder under consideration.

Irregularitics of the vascular system are frequently observed to arise from the presence of worms. Not twelve months ago I was consulted as to the curability of a young lady said to be labouring urder an affection of the heart. I found, in the case alluded to, an intermitting pulse, short-breathedness, tickling cough, and a countenance certainly not unlike the physiognomical expression of a person labouring under an affection of that vital organ. But on proceeding to an examination of tho alimentary functions, I was led to suspect that they were quite as much concerned as the heart, which might only be surfering sympathetically. The treatment for vermination was adopted, and I had the satisfaction not merely to see great numbers of worms which had been expelled, but to witness the young person's rapid restoration to health.

I have known some well-marked instances of gastric uneasincss being solely attributable to the presence of worms, and have been le? to think the lumbricus teres the usuai cause of uneasiness; as in two children I have witnessed this worm make its exit by the mouth much to the surprise of the by-standers. In these cases the symproms, in addition to the gastric pain, are those of worms generally, and grcat nausea more particularly.

The sympathy between the bladier and the alimentary canal is so frequently obsorved as scarcely to call for 1emark. When the latier is infested with worms to any great extent, the former is invariably listurbed; I shall therefore only on this point obserre, that the frequent disposition to urinate, and the thick milky state of the water might probably mislead, or be mistreated by, a practitioner who failed to bear in mind the intimate relations existing bctween the bladder and the intestines.

Maving in the above observations attempted to describe three varieties of vermination, our diagnosis ought not to be confinel to the distinctions between that complaint and others, but should extend to the inquiry,-How may we know the particular form before us?" In well-marked cases there is little difficulty, as, for instance, if a child, having great anal and nasal pruritus, be free from inordinate appetite, tumil ablomen, or disposition to cachexy, we may fecl assured the irritation is purely ascarideal. Again, if a child be cachexial to a great extent, have little of the pruritus just mentioned,-- have an inordinate liking for improner food and cold water, and he troubled with the before-described symptoms, in such a case 
great part of the intestinal tube is doubt- scription, he must produce his diploma of less affected by these parasitic animals. the "Baccalauréat ès-lettrés" to the chief Lastly, if a convulsive paroxysm, cerebral secretary, if he wish to inscribe himself as disorder, or particular abdominal pain, a student of the first class. In such case arise in a healthy-looking child, and be he pays fifty francs for each inscription, unaccountable except on verminative ex- and for that sum the lectures of the planation, the presence of the teretral faculty, all the hospitals, and the dissectvariety is indicated. Hence our diagnosis, ing-rooms, are open to him for three as to form of disorder in the majority of months. These inscriptions are renewed cases, approaches to certainty. But it does occasionally happen, that the bowels of a child are infested by two or even three varieties of worms at the same time. In such cases the symptoms are of a mixed character.

In conclusion, very little attention has been paid to the post-mortem appearances in this disease; a lamentable fact, too, easily as' ertained by reforence to the pages of Baillie in past, and Martinet in more recent times. One reason, doubtless, is the comparative infrequency of children dying solely from vermination; but still cases do occasionally present themselves, and should the author of the present contribution ever renture to resume the subject, it will be to direct attention to this much-neglected but interesting field of pathological inquiry.

\section{MEDICAL EDUCATION}

IN

\section{FRA NCE AND ENGLAND.}

To the Editor of The LANCET.

Sir,-In your able article of this week, you have omitted to mention some of the most important circumstances connected with melical education in France. Of these, the principal is, that, to every aspirant for the doctorate in the university of France, the degree of "Bachelor of Letters," as an evidence of a sufficierit general education, is an indispensable testimonial. This dcgree is equivalent to that of "Bachelor of Arts" in our universities, but in the Faculties of Letters in France the examination for it comprehends more subjects, and is far more searching, than in Oxford, Cambridge, or Dublin. The French Faculties, however, receive ad eundum, graduates in all foreign universities, and doctors in medicine of foreign universities are admitted to the same degree in France, on going through the formality of supporting a thesis. When the student attends at the office of the Faculty of Medicine in Paris, or in the other academies, to take out his first in- within the first fifteen days of every three months, if convenient to the student, but if not, he can let one or more terms pass and resume again. The students of the second class, or officiers de santé, pay but thirty francs for their inscriptions, and are not required to produce any evidence of having received a learned education, it being only necessary for them to make it appear that they can read and write.

These are facts but little known amongst our English students, and which prove very embarrassing to some of them who have the ambition to graduate in Paris. The preliminary step of the Baccalauréat èslettrés they find too difficult for them, being in general, though tolerable Latin and Greek scholars, deficient in algebra, mathematics, philosophy, geography, history, logic, and rhetoric, acquirements on which the French set a high value, and in which the candidate 3 are examined at the Faculty of Letters publicly, and in a manner that precludes all favouritism, and secures, at the same time, fair play to the examinant. It is owing to this "rascally" Baccalauréat és-lettrés, as the English students often express it, that so few of our countrymen graduate in Paris. Not having this degree, they inscribe themselves there on the footing of the Officiers de Santc, obtain certificates from the professors, whose presenting such documents is an act of courtesy, and then return to this country to graduate in the Scotch universities. The evidence of having received a learned general education is, then, a sine qua non, in the system of medical education in France, and had our "legally-constituted medical bodies" here exacted similar proofs, the profession would not be so encumbered as it is with drones, who live on the honey collected by the bees. "The heads" of the profession with us have hitherto profited by the ignorance of the mass, so that it has been a matter of policy with them to retard the progress and diffusion of medical knowledge. Things, however, are changing with a rapidity of which no student of the present day can form an idea; but $I$ and those who recollect how things were before The LanceT began to enlighten the medical world, know that a miraculous change has already taken place, and it must be admitted that that change is 